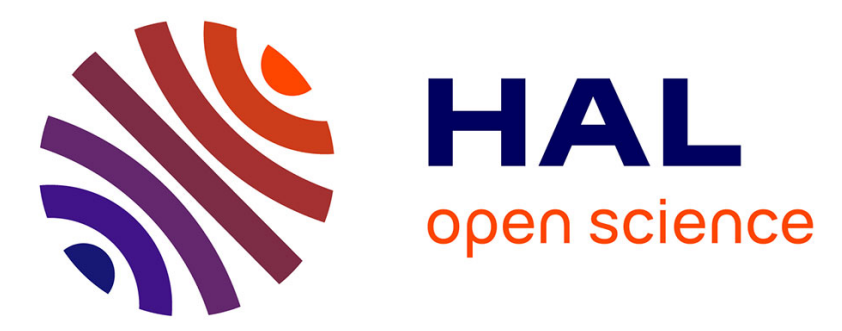

\title{
Educational trajectories after childhood cancer: When illness experience matters
}

A. Dumas, I. Cailbault, C. Perrey, O. Oberlin, F. de Vathaire, P. Amiel

\section{To cite this version:}

A. Dumas, I. Cailbault, C. Perrey, O. Oberlin, F. de Vathaire, et al.. Educational trajectories after childhood cancer: When illness experience matters. Social Science and Medicine, 2015, 10.1016/j.socscimed.2015.04.031 . hal-01148955v2

\section{HAL Id: hal-01148955 \\ https://hal.science/hal-01148955v2}

Submitted on 7 May 2015

HAL is a multi-disciplinary open access archive for the deposit and dissemination of scientific research documents, whether they are published or not. The documents may come from teaching and research institutions in France or abroad, or from public or private research centers.
L'archive ouverte pluridisciplinaire $\mathbf{H A L}$, est destinée au dépôt et à la diffusion de documents scientifiques de niveau recherche, publiés ou non, émanant des établissements d'enseignement et de recherche français ou étrangers, des laboratoires publics ou privés. 
Dumas A., Cailbault I., Perrey C., Oberlin O., Vathaire F. De et Amiel P., Educational trajectories after childhood cancer: When illness experience matters, Social Science \& Medicine, 2015. [doi:10.1016/j.socscimed.2015.04.031]

\title{
Educationaltrajectoriesafterchildhood Whenillnessexperiencematters
}

cancer:

Agnès Dumas ${ }^{a}$, Isabelle Cailbaulta, Christophe Perreya, Odile Oberlin ${ }^{b}$, Florent de Vathaire $^{c, d}$, e, Philippe Amiel ${ }^{\mathrm{a}}$

a Gustave Roussy, Department of ClinicalResearch, Social and Human Sciences Research Unit, Villejuif, F-94805, France

b Gustave Roussy, Department of Pediatric and Adolescent Oncology, Villejuif, F-94805, France

${ }^{\mathrm{c} C E S P}$ Centre for Research in Epidemiology and Population Health, U1018, Radiation Epidemiology Team, Villejuif, F-94807, France

d Gustave Roussy, Villejuif, F-94805, France

e Université Paris XI, Villejuif, 94800, France

\begin{abstract}
With the increase in survival from childhood cancer, research has increasingly focused on the educational and professional achievements of childhood cancer survivors. Yet, if large-scale studies provide an acute description of the current situation of childhood cancer survivors, little is known about their trajectories and the social processes shaping these trajectories.

Using a qualitative methodology, drawing from a life course perspective, this study sought to describe the role of childhood cancer and its side effects in educational trajectories, as perceived by the participants. We investigated related processes of social adjustment to cancer, that is to say, choices or decisions that survivors related to the illness in the making of their career plans. Eighty long-term French childhood cancer survivors participating in the Euro2K longitudinal study were interviewed through in-depth, face-to-face interviews undertaken in 2011-2012.

There were various types of impact described by respondents of the diagnosis of cancer on their occupational trajectories. These varied according to gender. In women, childhood cancer tended to result in poor educational achievement, or in steering the individual towards a health care or child care occupation. This was justified by a desire to return the support that had been offered to them as patients. In men, however, childhood cancer led to a shift in career plans, because of physical sequelae, or because of concerns about their future health. Paradoxically, this limitation had a positive impact in their occupational achievement, as most of these men disregarded blue-collar jobs and chose more qualified white-collar occupations. Overall, findings suggest that childhood cancer influenced educational trajectories and, thus, socioeconomic status in adulthood, through mechanisms embedded in gender norms. These mechanisms could explain gender inequalities in educational achievement after childhood cancer reported in large-scale cohort studies.
\end{abstract}

Key words: France; Childhood cancer; Survivorship; Education; Work; Trajectory; Life course; Social health inequalities

\section{Introduction}

Medical advances over the past four decades have prolonged survival from childhood cancer. This progress has been achieved throughthe use of multimodal and aggressive treatments. Nowadays, about $80 \%$ of children with cancer survive the disease, but $40 \%$ of survivors have 
late adverse effects (Oeffinger et al., 2006). With the increase in survival from childhood cancer, research has been growingly focused on the educational and professional achievements of childhood cancer survivors (De Boer, Verbeek, \& van Dijk, 2009). Largescale studies conducted in Europe and Northern America have found mixed results, showing a lower, better, or similar educational achievement of survivors, compared to that of controls (Boman, Lindblad, \&Hjern, 2010; Dieluweit et al., 2011; Gurney et al., 2009; Kelaghan et al., 1988; Koch, Kejs, Engholm, Johansen, \&Schmiegelow, 2004; Kuehni et al., 2012; Lorenzi et al., 2009; Pastore et al., 2001). Brain tumor survivors, on the other hand, have systematically been found at risk of poorer social outcomes (Lund, Schmiegelow, Rechnitzer, \& Johansen, 2011). In addition, many studies have underlined a lower educational or occupational achievement of female survivors compared to male survivors (Kirchhoff et al., 2011; Koch et al., 2004; Lancashire et al., 2010; Lorenzi et al., 2009; Mitby et al., 2003). However, a weakness of this body of research is that no study has included a longitudinal perspective. These large-scale studies provide an acute description of the current situation of childhood cancer survivors, but little is known about their trajectories and the social processes shaping these trajectories.

The health selection explanation, which states that poor health prevents upward social mobility, has occupied a minor place in the studies of health inequalities (West, 1991). The stunting variant of the health selection hypothesis argues that poor health during childhood may limit an individual's initial accumulation of human capital and subsequent access to higher social positions (Haas, 2006; Palloni et al., 2009). Besides the poorer academic performances due to frequent absenteeism from school during periods of illness and hospitalization, several possible mechanisms are under consideration. The interruption caused by the disease might constitute a disadvantage for interacting with peer groups, or might delay opportunities to explore personal and occupational interests. Moreover, poor health in childhood might influence educational aspirations, resulting in a reduced projection in longterm educational goals. Indeed, lifestyle choices may be significantly altered by cancer and its after-effects. Fear of recurrence and the burden of health conditions induced by treatment toxicities might influence survivors in their planning about education plans, and, therefore, might negatively affect their educational and occupational achievement.

Some studies have attempted to assess this latter mechanism through questionnaires or interviews made with young patients recovering from childhood cancer. They showed that young survivors could report a negative impact of cancer on their vocational aspirations 
(Badell et al., 1998; Gerber et al., 2006; Servitzoglou, Papadatou, Tsiantis, \&VasilatouKosmidis, 2008), lower professional expectations or less concrete plans for the future (Boman\&Bodegård, 2004; Gerhardt et al., 2007; Servitzoglou et al., 2008), or a change in their career plans resulting from cancer(Felder-Puig et al., 1998; Servitzoglou et al., 2008). However, most of these studies were conducted during the transition from adolescence to emerging adulthood, with young survivors who had not necessarily completed their education, lacking perspective in their career and in their life course.

Through in-depth interviews with a large sample of long-term adult survivors, the aim of this qualitative study was to describe the perceived role of childhood or adolescent cancer and its side effects in educational trajectories. Drawing from a life course perspective (Giele and Elder, 1998), we retrospectively investigated processes of social adjustment to cancer, that is to say, choices or decisions that survivors related to the illness in the making of their career plans.

\section{Materials and Methods}

\section{Theoretical framework}

In our study, we were interested in the concept of "trajectory". In the life course perspective, this concept is mobilized to describe the sequence of social positions occupied by individuals within a period of time or within a defined domain of social life. Qualitative methods provide in-depth insight into the fabric of social trajectories, the longitudinal interrelation between events, and the social contexts in which they take form. Indeed, the life course paradigm does not deny the importance of structural forces at play. In fact, life courses are commonly seen by sociologists as the result of highly complex processes operating at multiple levels, which means to take into account the embedding of individual lives into constraints and opportunities dependent on the social positions of actors (Mayer, 2009). In our study, in accordance with a long sociological tradition (Weber, 1978), we were more specifically interested in the action-theoretic level of explanation within these trajectories which emphasizes the meaning that individuals attach to their own actions. Hence, processes of social adjustment to childhood cancer were considered as the actions (choices, decisions, strategies) in which individuals had integrated the subjective experience of childhood cancer. 


\section{Study participants}

Study participants were French members of the Euro2K cohort, an international on-going longitudinal study which started in the 1990s to assess adverse effects of cancer treatment. Participants in this cohort were treated for solid tumors or lymphoma between 1948 and 1985, when they were children or adolescents ( $<18$ years old). Eligibility for and recruitment to the cohort has been described elsewhere (De Vathaire et al., 1995)(. Some of the original participants were excluded however, because of diagnostic errors and duplicates, and some others have been added, who were initially missed because some medical records were not available at the time of the initial cohort constitution, but were discovered during a systematic investigation of hospital archives performed afterward. In 2011, 2,456 patients were considered as eligible patients (e.g., alive at time of study), of whom 1,920 agreed to participate in the follow-up study.

For the qualitative arm of the study, patients treated before 1970 were excluded in order to reduce discrepancy in age and period of treatment as well as survivors treated for central nervous system tumors because of the late cognitive effects and the specific challenges they face (Boydell, Stasiulis, Greenberg, Greenberg, \&Spiegler, 2008; Duffner, 2010). Among the remaining participants $(n=1389)$, a sample was constructed using random selection, with age at diagnosis strata $(<7$ years, $\geq 7$ years $)$ in order to over-represent survivors treated when they were seven years old or more, e.g., survivors who might have a more accurate memory of their illness than survivors treated at a younger age. We sent recruitment letters to 160 participants and were able to contact 97 (60.6\%). Of those contacted and eligible, $80(82.5 \%)$ participated. Six persons refused to participate and the interview could not take place in spite of agreement in 11 cases.

\section{Data collection and analysis}

We first made an explorative qualitative study in 2011, using life history interviews, eliciting personal narratives, with 17 adult survivors. The analysis of these interviews provided the relevant categories to conceive a comprehensive semi-structured interview guide. This explorative study also revealed a great variability in situations of childhood cancer survivors. The number of subsequent interviews was high $(n=63)$ in order to stratify analysis by different subgroups according to type of cancer, age at diagnosis, and physical sequelae related to cancer.

The interview guide was divided into two parts. The first part covered the history of the disease and the immediate and long-term after-effects of cancer, as well as other health 
problems (health trajectory). The second part of the guide dealt with the perceived impact of cancer on social life, and, in particular, in the educational and vocational domains (social trajectory). Even in semi-structured interviews, interviewers let participants articulate their perceptions and experiences freely and spontaneously as much as possible. The subjective experiences of participants were considered as central. Thus, participants were not given any indication of a positive or a negative impact, but rather were asked if they perceived any impact of childhood cancer in their life. At the end of the interview, information on parental social status (e.g., occupation of both parents) and current socioeconomic position of survivors (level of education and occupation of survivors) was systematically recorded if it had not been spontaneously mentioned during the interview. Occupation was classified according to the French classification of occupation (PCS 2003) whose categories are considered as proxies of the social class (Desrosieres, 2009).Medical data concerning childhood cancer (type of cancer, year and age at diagnosis, type of treatment) was obtained from medical records. All other data came from the interviews. Three members of the research team $(\mathrm{AD}, \mathrm{IC}, \mathrm{CP})$, all trained in qualitative health research, conducted the 80 indepth, face-to-face interviews in 2011-2012. Interviews lasted one hour and a quarter, on average. All were tape recorded and transcribed.We used an inductive approach in data analysis (Strauss \& Corbin, 1998). We followed the pattern coding approach suggested by Miles and Huberman(Miles \&Huberman, 1994), which involved data reduction (extracting the essence), data display (organizing for meaning), and drawing conclusions (explaining the findings). Five exploratory interviews were coded collectively. The remaining transcripts were coded by AD and IC. Questions or discrepancies were resolved through discussion during regular meetings of the research team. Content analysis was computer assisted with qualitative data analysis software (Nvivo9). The study received approval from the national commission controlling data collection in France (CNIL) and from the Ethics Committee of the French National Institute of Medical Research and Health (INSERM). Informed consent was obtained from all participants for inclusion in the study. Names reported in this article are pseudonyms.

\section{Results}

Gender, type of cancer, and type of treatment were quite similar between the participants of the qualitative study and the participants of the Euro2K cohort, with the exception of survivors who were treated for soft tissue sarcoma, who were significantly under-represented in the qualitative study, whereas survivors of gonadal tumors were over-represented (Table 1). 
Table 1. Characteristics of Euro2K participants a, according to sampling and participation into the qualitative study (\%)

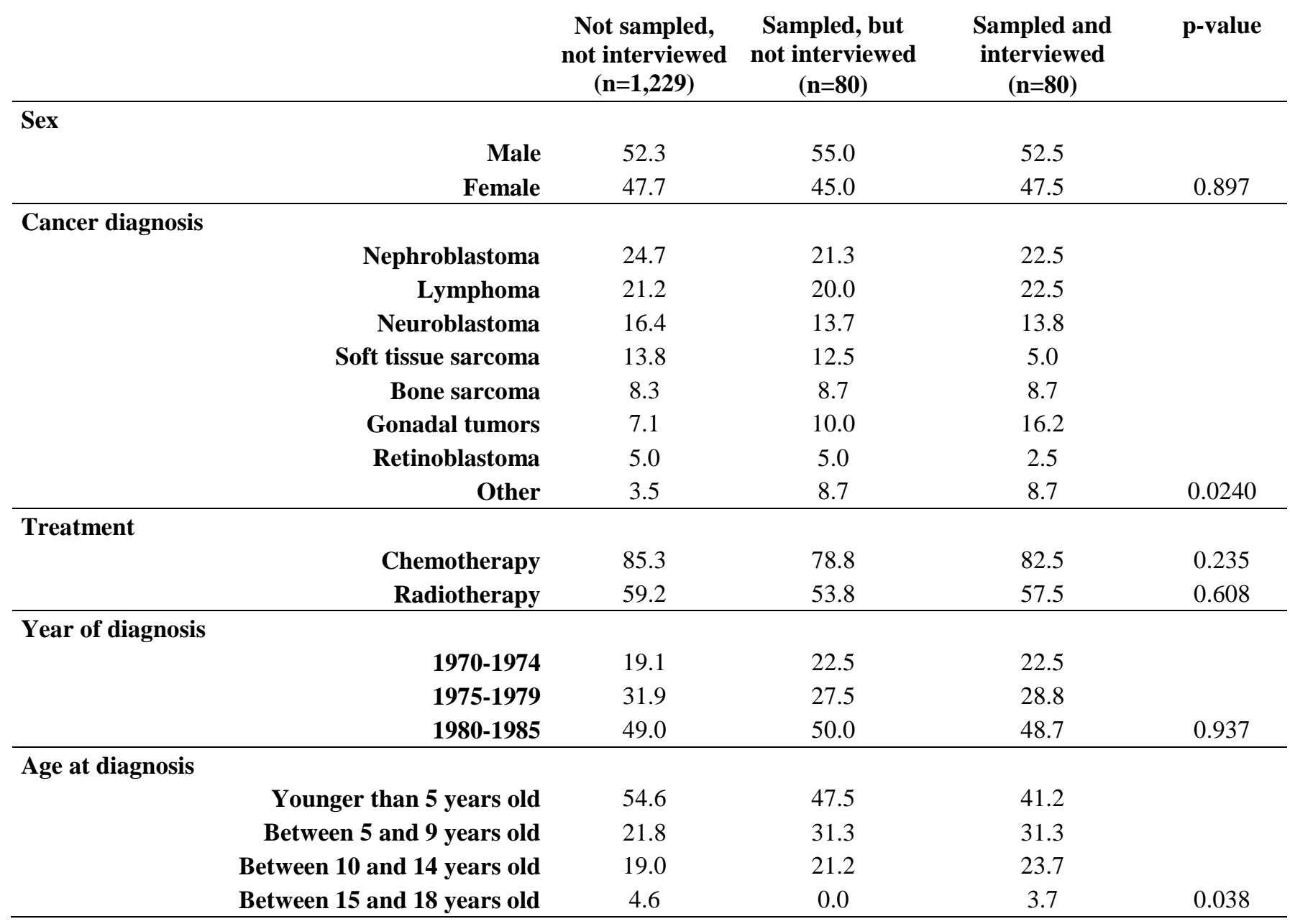

\footnotetext{
${ }^{a}$ Survivors treated for solid tumors or lymphoma between 1970 and 1985, with the exception of CNS tumors.
}

Participants in the qualitative study were older at time of diagnosis because of the sampling strategy. Time elapsed since diagnosis ranged from 27 years to 42 years (mean: 34); mean age at time of interview was 38 years (range 27-53). At the time of study, 69\% of participants reported physical sequelae related to their childhood cancer; $19 \%$ of participants received economic compensation in relation to these sequelae. Adverse effects of treatments included cardiac and/or pulmonary diseases, functional limitations due to amputation, atrophy caused by radiotherapy resulting in severe musculoskeletal disorders. Sixteen survivors reported a relapse or a recurrence of cancer-half of them during childhood or adolescence.

Four participants had a cognitive deficit or a mental illness unrelated to their cancer. For instance, Emma, who had meningitis before her diagnosis of childhood cancer, had both mental and physical limitations which prevented her from going to school and from working. She has been receiving disability benefits since she was 18 years old. Another survivor, who 
had osteosarcoma and lung metastasis and underwent an amputation and five lung surgeries, was also declared as a person with disabilities when she was 18 years old, mainly because of her respiratory insufficiency. She has been receiving disability benefits ever since. The health condition of these four individuals (beyond cancer and its late effects) obviously affected their educational and occupational trajectories. As the aim of this study was to understand how childhood cancer could influence survivors' choices in education and work, these four participants have been excluded from the analysis presented hereafter.

Among the remaining participants $(n=76), 30 \%$ of participants $(n=24)$ reported that childhood cancer had influenced their choice of education and career, while the others $(n=52)$ thought that cancer had no role in their trajectory. Three types of perceived impact emerged from the data, with a clear gender pattern: cancer was seen by women as a reason for leaving school (5\%), or for choosing one's career (14\%), whereas men tended to perceive cancer as a limiting factor in their career aspirations (12\%).

\section{Cancer as a reason for school dropout and early entry into working life}

Half of the participants attended school when they were treated (being in $1^{\text {st }}$ grade or higher). Altogether, $24 \%$ of participants repeated a year (or more) because periods of illness and hospitalization prevented them from attending school for several months. Most of those who repeated a year because of the disease (16/18) thought that cancer did not have a decisive impact on their educational achievement. Some of them did not even remember which grade they repeated, especially when they were young at the time of the diagnosis.

Whether they repeated a year or not, four women, diagnosed when they were preadolescents or adolescents ( $\geq 9$ years old), perceived cancer as a reason for school dropout and as an explanation for their "early entry" into working life. Rather than a direct and simple impact of treatment duration and constraints on scholastic functioning, they reported a "disinterest in school" during adolescence that they presented as a consequence of the traumatic experience of childhood cancer. None of them suffered from adverse physical effects of treatments. Yet, they mentioned important school absenteeism during adolescence that was known and tolerated by their parents. They related their absenteeism to psychological distress and difficulties in coping with the illness experience. None of them received psychological support during this critical period. At school, all felt that they were "on $a$ different wavelength" than their counterparts. Conversely, they all considered an early entry into working life (e.g., after compulsory education) as a positive transition into adulthood. Two of them were born to wealthy families, the other coming from middle-class families. The 
four of them stopped studying when they were less than 20 years old; only two of them (the ones with the highest social background) completed high school. All did "on-the-job" training.

The story of Marianne provides an example of these school dropouts. Marianne was treated in 1985 for a gynecological cancer, by the age of 14. Like many other participants in this study, Marianne experienced a long and painful treatment during which her mother stopped working. Marianne considered school differently after she recovered: she was "not interested in school". By the end of high school, although her grades would have allowed her to go to university, she wanted to work "as soon as possible" in order to become an autonomous adult. Her parents did not interfere with her projects and did not "putpressure on her" as a result of her cancer history. By the age of 20, she found a summer job in fashion, and managed to have acareer in that domain. At the time of the interview, although she valued her career, she showed some regrets for not going to university:

Marianne: "My parents were so happy, and especially my mother, they were so happy that I was alive, I think I could have done anything, I could have failed exams every day, they would have been absolutely delighted! So... My parents never put pressure on me, about education. And well, now, I regret it."

Marianne came from a wealthy family where "everyone goes to college". By pointing out the lack of "pressure" from her parents as a determinant in her trajectory, Marianne's account underlines the fact that cancer had not only had her educational goals changed, it had also influenced her parents' expectations. Compared to the occupational category of both her father and mother, the trajectory of Marianne illustrates a downward intergenerational mobility. Likewise, the three other women reporting an early transition into working life mentioned a lack of involvement, on the part of their parents, in their educational achievement. Two of them also showed downward intergenerational mobility.

\section{Choosing one's career in health or in childcare through cancer experience}

Out of 13 participants working in health or childcare, 11 said that they chose their occupation because of their experience of a pediatric illness. They became teachers $(n=1)$, child caregivers $(n=3)$, nurses $(n=3)$, doctors or researchers $(n=3)$, or laboratory assistants $(n=1)$; almost all of them (10/11) were women. Survivors who chose to work in health-related fields 
were older when cancer was diagnosed (at least 7 years old) than those who chose to work in childcare professions (who were almost all 5 years old or less).

Whetherthey chose a health environment or childcare, all of these survivors related their career choice to a desire to "give back" and to "help others". One woman stated that "what she had been through had left such a mark on her" that she decided to become a school teacher for sick children as she was only ten years old, a couple of years after she had recovered from a Wilm's tumor. If child caregivers said that their illness experience was one of the reasons that accounted for their choice of career, health professionals drew a stronger link between their childhood illness and their educational and vocational paths, referring their choice to a desire to "understand" cancer.Elisabeth wanted to be a doctor when she was an adolescent, because she felt she had some kind of debt towards the doctors who cured her. She finally chose to study biology after high school, in order to "understand what had happened". She became a clinical researcher in the pharmaceutical industry.

Elisabeth: "Career choice was strongly influenced by the illness! I have no doubt about that. First, when I grew up, I got interested in my story, and, then, I got interested in biology, to understand what had happened. First, I chose to become a doctor. In some way, I think it was about giving back what had been given to me... Well, I mean... They saved my life."

Some of the participants also outlined the fact that the long time they spent in hospitals because of their childhood cancer gave them the opportunity to encounter the medical setting and to discover the medical profession. One woman who had serious cardiac late effects because of cancer treatment stated that "ever since I was a little girl, the hospital, the world of care, it has been my second home". Another woman, who failed to become a physician, chose to be a physiotherapist. She explains her choice by the combination of all those motivations:

Martine: "[This choice of career] is related to a will to understand the disease, maybe also to help others or to give back... Because there was nobody to influence me in this choice! I did not have any uncle or aunt... There was nothing around me to drive me there, so I think that yes, this context, the fact that I spent so much time... It did play a role."

Martine asserts that she may have chosen to work in healthcare because she became familiarized with the medical setting during her hospitalizations. Those hospitalizations were 
indeed numerous during her childhood and adolescence-as it was for about one out of five participants of the study. In 1970, Martine underwent surgery, chemotherapy, and radiotherapy to treat her cancer, when she was 9 years old. Five years later, she underwent surgery because a thyroid cancer was suspected. Radiotherapy received for the treatment of her first cancer caused fibrosis of her femoral artery, and she underwent artery bypass surgery when she was 15 years old. Martine underlines the absence of family "influence" in her choice of career. Her father, a company director, and her mother, a housewife, did not disagree with her desire to become a physician, neither did they expect Martine's younger sisters to follow the path of their eldest daughter. Similarly, the other participants who reported cancer as a vocational support stated that their family did not influence their career choice. Apart from one woman whose mother was a nurse, none of these survivors had a mother or a father working in health or childcare sectors.

\section{Cancer as an obstacle in career aspirations, resulting in an upward social trajectory}

Nine survivors reported that cancer had been an obstacle to choosing a career when they were adolescents or young adults, mostly men (7/9). Most of these survivors (6/9) gave up a career planbecause of objective physical sequelae. Four of them had their leg amputated or their eye removed because of osteosarcoma or retinoblastoma, one survivor had a serious cardiac disease caused by chemotherapy (which later required a heart transplant), and another survivor had significant musculoskeletal disorders following chest radiation. All of these sequelae appeared before the age of 20, that is to say, during adolescence or young adulthood, when their career exploration was in progress. For instance, Denis, who lost an eye after a retinoblastoma, in 1980, when he was only a few months old, became a sales clerk instead of a motorcar mechanic because his father considered that a garage was not an appropriate environment for his remaining eye.

Other survivors abandoned their career project because of a concern about their future health, though they did not have any physical objective sequelae at the time of career choice (3/9). Frederic, who had lymphoma in 1984, when he was 10 years old, had no physical sequelae related to cancer, nor other chronic condition. Nevertheless, when he was an adolescent, his parents did not approve of his desire to work as a motorcar mechanic, arguing that being exposed to chemical products in a garage was not safe, considering his childhood cancer. Instead, he became a building caretaker-choosing, like Denis, an occupation with a higher social position than the initial one, considering the French classification of occupation. One case of discrimination was also reported. Although he was a judoka black belt, a man 
was denied access into the army because he was missing a kidney after a Wilms' tumor: "I was like everyone... I was a judoka black belt. I had never been told not to do something because of cancer. So it was hard... It was the only time in my life when I felt injustice because of my cancer." A few months after that, he found a job as a salesman and rapidly became a manager. Again, this change in career plans led to choosing an occupation with a higher position on the classification of occupation.

This limitation of possibilities, mainly cited by men (7/9), had a paradoxical positive impact on their occupational achievement as they gave up manual or physical professions (typically male-oriented blue-collar jobs) to choose less physical and more qualified jobs, with an upper position on the social ladder. These men all considered cancer as a negative obstacle during adolescence or young adulthood, when they gave up their original career project, but were currently satisfied with their 'second' choice of work and their current career. In particular, those who had health problems thought that their initial choice of bluecollar job could have been a "wrong" choice. For instance, Denis, who gave up the plan to be a motorcar mechanic because his father thought he would not have a safe working environment considering he had just one eye, said that "in the end, after all these years, [I think that] my father was not that wrong. It is true than in a garage, you are exposed to detergents, to chemical products, to dust, and, for the eyes, it ain't good".

On the other hand, two women, who felt that they chose less qualified jobs because of their cancer history, were not satisfied with their current position. Unlike the other participants, Sabine explicitly said that she chose not to go to college because she thought she had a reduced life expectancy. She developed this belief after talking with a school doctorwhen she was about 14 years old, three years after she was treated for lymphoma, in 1982. Although she did not have any physical sequelae related to cancer nor other chronic condition, this doctor suggested to her that she should take her history of cancer into consideration in her choice of occupational pathways.. After high school, she started studies to become a secretary, which she abandoned after one year and yet found a job in that domain a few months after.

Sabine: "I think this was a turning point. Because I was a good pupil! And yes, it is that [what the school doctor had said]... I think it was an obstacle. I told myself: "So, I cannot do everything I want?” So, it was a kind of obstacle... And well, maybe I closed some doors... by myself... regarding choice of occupations." 
Fear of recurrence and premature death was a recurrent topic in survivors' accounts, whether their fear began as they were adolescents or as they were aging. Yet, Sabine was the only participant to report that she did not project herself in long-term educational goals because she thought she would die young.

\section{Discussion}

According to the health selection hypothesis, poor health in childhood may result in reduced initial accumulation of human capital and in lower subsequent socioeconomic status in adulthood, thus partly explaining social inequalities in health (Haas, 2006; Palloni, 2009). Possible mechanisms include reduced school performances related to lost time of schooling or lessened projections in long-term educational goals. Childhood cancer, as it may induce fear of recurrence and uncertainty about life expectancy, constitutes an appropriate context to explore this latest mechanism. Life course perspective can provide a substantial contribution in this area of research because of its capacity to investigate mechanisms operating across the different stages of life, and to explore the way individual processes are related to macrostructural outcomes (Mayer, 2009). This study aimed to identify such mechanisms (Elster, 1989; Hedström\&Swedberg, 1998), defined as processes of social adjustment to childhood and adolescent cancer, in educational paths and career related choices, in order to better understand the impact of this childhood illness on educational or occupational achievement.

Accounts of survivors showed that, for most participants, grade repetition during the treatment phase of the disease was not perceived as ultimately affecting their educational and occupational achievement. Besides, although fear of relapse was a recurrent theme in interviews, only one woman expressly stated that she had not projected herself in long-term educational goals because of a fear of a reduced life expectancy. Nonetheless, poor psychological coping during the illness and the years that followed was reported as a disruption in the educational trajectory by four women, driving them slowly toward a school dropout and an "early" transition into working life. All mentioned that they lacked psychological support during adolescence although they were treated in the 1980s, at a time when supportive care was more often provided than in the 1970s. This early entry into working life resulted in a de facto poor educational attainment, which is consistent with a previous Swedish study which showed that poor psychological coping (assessed through indepth interviewing with psychologists) was associated with shorter education (Boman\&Bodegård, 2004). Furthermore, all were women treated when they were pre- 
adolescents or adolescents. Female survivors are precisely identified in the literature as a vulnerable group compared to male survivors: they tend to perceive their cancer experience as more difficult and more stressful, and are at greater risk of psychological distress (Langeveld, Grootenhuis, Voûte, de Haan, \& van den Bos, 2004; Zeltzer et al., 2009). Likewise, survivors diagnosed as adolescents have also been found to present a greater psychological distress than those diagnosed earlier (Kazak et al., 2010). Adolescence is a time of transition and vulnerability as well as a critical period in career exploration (Super, 1957). Yet, if these women lacked psychological support during this critical period, their accounts also reveal a lack of stimulation on the part of their parents. A large amount of sociological and psychosocial research has shown the role of parents in choice of career and, thus, in the status attainment process, whether through socially structured pathways (Boudon, 1974) or gendered parental expectations (Eccles, 1994). These women were treated in the early 1980s, at a time when childhood cancer was still a fatal disease in a significant number of cases. The fact that these women (who were often, in addition, lonely children) survived from this illness most likely changed the way their parents envisioned the future of their offspring, resulting in decreased academic expectations, as in the case of Marianne's mother, who was "delighted" no matter what her daughter's academic performances were or whatever her career choice was, because she was already "happy" enough with the survival of her daughter.

A second type of social adjustment to childhood cancer consisted in a choice of career in heath environment or child care, supported by the experience of the illness. Other qualitative studies have reported an initial orientation of childhood cancer survivors toward health care careers (Brown et al., 2008; Eiser et al., 1997). Brown et al., in their interview study of young leukemia survivors, also found that survivors who were attracted by healthcare careers reported a "desire to give back" (Brown et al., 2008). The authors thought that the choice of these young survivors could reflect a process of familiarization with the medical environment. This process was explicitly outlined by some interviewees of our study ("the world of care is my second home"; "I spent so much time there"...). One remarkable finding lies in the fact that women who were treated when they were very young ( $<5$ years old $)$, who sometimes barely remembered the event, also reported that they constructed their professional identity in relation to the illness experience by working in childcare. Many studies have found that cancer deeply affects young survivors in the construction of their self and their identity (Parsons, Eakin, Bell, Franche, \& Davis, 2008; Phillips \& Jones, 2014; Prouty, Ward-Smith, \&Hutto, 2006). Corbin and Strauss proposed the concept of 'biographical adjustment' to describe the work people with chronic conditions do to integrate the changes induced by the 
disease (Corbin \& Strauss, 1988). Far from being limited to the way individuals deal with the daily constraints of the illness, biographical adjustment can imply a profound reorganization of identity. However, Strauss and Corbin rightly underline that this biographical adjustment depends on the resources of the actor, which are constrained by his social position. Narratives are precisely the place where the actor can ensure the consistency of his actions and give a sense of coherence to his life. In fact, every biographic research is confronted with the question of the ex post reconstruction of the meaning and the coherence of narratives (Ricoeur, 1984). Accounts of these women who said they chose caring professions might indeed illustrate what G. Williams named as a process of 'narrative reconstruction' by which interviewees have elaborated reconstructions of their experience in such a way that illness could be given a place within it, "in order to understand the illness in terms of past social experience and to reaffirm the impression that life has a course and the self has a purpose" (Williams, 1984, p. 179).

A third type of mechanism was that cancer appeared as an obstacle, mostly for men, who abandoned an initial choice of a blue-collar vocation. Consistent with previous research (Boman\&Bodegård, 2004; Brown et al., 2008; Eiser et al., 1997; Felder-Puig et al., 1998; Gerber et al., 2006; Gerhardt et al., 2007; Servitzoglou et al., 2008), survivors of our study also perceived cancer as an obstacle in the making of their educational plans. Our study emphasizes the role of immediate and medium-term objective effects of cancer on these feelings of work limitations, as most of the survivors reporting cancer as an obstacle had to face the physical sequelae of cancer before they reached the age of 20 , often because of retinoblastoma or osteosarcoma, cancers that could lead respectively to amputation. Considering that many blue-collar occupations, which require little or no education, may be impossible with an amputated leg or serious musculoskeletal disorders, it is likely that survivors affected with those sequelae when they are adolescents show increased motivation in engaging in mid- or long-term educational plans that will give them access to non-physical occupations, increasing their chance to belong to higher social groups in adulthood. Interestingly, subjective beliefs could also interfere, and, notably, perceptions of risks related to chemical exposures in the occupational environment, which are also more prevalent in male-oriented, blue-collar jobs. In contrast to the previous publications cited above, our study considered a timeline of 27 to 42 years after treatment. Hence, it provided an opportunity to see the long-term implications of those changes in work aspirations. Indeed, given the socioeconomic and health benefits derived from higher education and from higher occupational achievement (Ross \& Chia-Ling, 1995), these limitations in career plans could 
have an unexpected positive impact on the occupational attainment, when it comprised choosing a less physical and more qualified occupation than the initial one.

Across time periods and nations, statistics of surveys indicate that women choose jobs that conform to the cultural stereotype of female occupations (such as nursing, teaching, and caring for young children) while jobs which have a stereotypical male orientation (like police work or auto mechanics) draw more men than women, resulting in a horizontal occupational segregation (Charles \&Grusky, 2004). Beyond gender essentialism, which posits that men and women are fundamentally and essentially different, Eccles and her colleagues have underlined the role of gender role socialization in this occupational segregation, showing how men and women choose different career paths due to differences in self-perceptions, goals, and values linked to normative ideas about gender identity (Eccles, 1994; Schoon\&Eccles, 2014). Accounts of the women who chose caring professions might thus reveal their embedding within wider social macro-structures, and in particular in gender norms. Still, the aim of this study was to understand how the illness was incorporated into educational strategies, and what the consequences of this integration could be. Whether illness did play a role in the career decisions of these women, one important thing is that their choice of caring professions was in accordance with their gender identity. On the contrary, for boys, cancer prevented their engagement in typically male-oriented occupations (motorcar mechanic, army). Therefore, the key finding of our study was that gendered mechanisms modulated the impact of cancer experience on educational trajectories and, thus, socioeconomic status in adulthood: what men described as a limitation often led to shift their initial choice of male-oriented blue-collar jobs (e.g., occupations in accordance with their gender identity) toward white-collar occupations, which offer better chance of social promotion; conversely, for women, the impact of cancer either fitted their gender identity or either resulted in an early entry into the workforce, and, therefore, in a poor educational achievement. Itfinallyappears that social adjustments topediatriccancermay havecontributed,to an extentthat the results ofthe Euro2K cohortwill measure, a form of upward social mobility for men, with regard to female survivors. These gendered mechanisms could notably explain gender inequalities in educational and occupational achievement after childhood cancer observed in many international large-scale studies, whether they were conducted in the US, Canada, or Europe (Kirchhoff et al., 2011; Koch et al., 2004; Lancashire et al., 2010; Lorenzi et al., 2009; Mitby et al., 2003).

This study had some limitations that should be taken in account. The sample of the study was drawn from a large longitudinal cohort, the Euro2K study, which includes 
survivors of solid tumors or lymphoma treated until 1985. Therefore, we could not interview survivors of other types of cancers such as the common hematological cancer, leukemia. The sample of the qualitative study purposively excluded survivors of brain tumors, who are particularly at risk of poor social outcomes, because of the specific and unique challenges they experience (Boydell et al., 2008). Furthermore, participants were treated during a period when medical treatment was different from that of today, and mortality was higher. Therefore, this study offers a time-limited exploration of the perceived impact of childhood cancer in choice of education and career and may not reflect the experience of survivors writ large.

\section{Conclusion}

Qualitative methods capture the subjective meaning of experience that cannot be completely described by quantitative survey methods. By retrospectively exploring life courses of childhood cancer survivors, this study identified mechanisms possibly explaining gender inequalities in educational and occupational achievement after cancer. Such a mechanism is the adjustment of career goals to the perceived impact of cancer, which, in turn, can determine educational and occupational achievements. In particular, for boys, an inadequacy between health and choice of male-oriented physical blue-collar occupations could result in a form of upward social mobility, with regard to female survivors. Thus, our results give an insight into complex - and possibly paradoxical or counterintuitive-mechanisms underlying the health selection effect.

These modulating mechanisms need to be further explored in different historical and geographical contexts. At least, they underline the need to integrate a longitudinal perspective and to investigate social adjustment processes - that is to say, choices or decisions in which illness experience is incorporated - to better understand the impact of cancer on educational achievement, as well as the role of health over the life course.

\section{Disclosure statement}

There is no conflict of interest arising from this work for any of the named authors.

\section{Acknowledgements}

Authors would like to thank all the participants of the study. Authors would like to thank Philippe Oliviero and Imad Yagoub for their participation in data analysis. This research 
('VVSK/SurviCan') was granted by the 'Liguenationalecontre le cancer' and by the 'Canceropole Ile-de-France'.

\section{References}

Badell, I., Igual, L., Gomez, P., Bureo, E., Ortega, J. J., Cubells, J., ... Bayés, R. (1998). Quality of life in young adults having received a BMT during childhood: a GETMON study. Bone Marrow Transplantation, 21(Suppl 2), S68-71.

Boman, K. K., \&Bodegård, G. (2004). Life after cancer in childhood: social adjustment and educational and vocational status of young-adult survivors. Journal of Pediatric Hematology/oncology, 26(6), 354-362.

Boman, K. K., Lindblad, F., \&Hjern, A. (2010). Long-term outcomes of childhood cancer survivors in Sweden: a population-based study of education, employment, and income. Cancer, 116(5), 1385-1391.

Boudon, R. (1974). Education, Opportunity and Social Inequality. New York: Wiley.

Boydell, K. M., Stasiulis, E., Greenberg, M., Greenberg, C., \&Spiegler, B. (2008). I'll show them: the social construction of (in)competence in survivors of childhood brain tumors. Journal of Pediatric Oncology Nursing, 25(3), 164-174.

Brown, C., Pikler, V. I., Lavish, L. A., Keune, K. M., \&Hutto, C. J. (2008). Surviving childhood leukemia: career, family, and future expectations. Qualitative Health Research, 18(1), 19-30.

Cantrell, M.A., \& Conte, T.M. (2009). Between being cured and being healed: the paradox of childhood cancer survivorship. Qualitative Health Research, 19, 312-322.

Charles, M., \&Grusky, D. (2004).Occupational Ghettos: The Worldwide Segregation of Women and Men. Stanford: Stanford University Press.

Corbin, J. M., \& Strauss, A. (1988). Unending work and care: managing chronic illness at home. San Francisco: Jossey-Bass.

De Boer, A., Verbeek, J. H., \& van Dijk, F. (2009). Young Survivors of Childhood Cancer. In Work and Cancer Survivors (Feuerstein M., p. 163-188). New York: Springer.

Desrosieres, A. (2009). Socio-occupationalcategories. Courrier des statistiques, English series, 15, 13-15.

De Vathaire, F., Shamsaldin, A., Grimaud, E., Campbell, S., Guerra, M., Raquin, M., ... Rumeau, N. (1995). Solid malignant neoplasms after childhood irradiation: decrease of the relative risk with time after irradiation. Comptes Rendus de l'Académie Des Sciences. Série III, Sciences de La Vie, 318(4), 483-490.

Dieluweit, U., Debatin, K.-M., Grabow, D., Kaatsch, P., Peter, R., Seitz, D. C. M., \&Goldbeck, L. (2011). Educational and vocational achievement among long-term survivors of adolescent cancer in Germany.Pediatric blood \& cancer, 56(3), 432-438.

Duffner, P. K. (2010). Risk factors for cognitive decline in children treated for brain tumors. European Journal of Paediatric Neurology, 14(2), 106-115.

Eccles, J.S. (1994). Understanding Women's Educational and Occupational Choices. Psychology of Women Quarterly, 18(4), 585-609.

Eiser, C., Cool, P., Grimer, R. J., Carter, S. R., Cotter, I. M., Ellis, A. J., \&Kopel, S. (1997). Quality of life in children following treatment for a malignant primary bone tumour around the knee.Sarcoma, 1(1), 39-45.

Elster, J. (1989). Nuts and Bolts for the Social Sciences. Cambridge: Cambridge University Press. 
Felder-Puig, R., Formann, A. K., Mildner, A., Bretschneider, W., Bucher, B., Windhager, R., ... Topf, R. (1998).Quality of life and psychosocial adjustment of young patients after treatment of bone cancer.Cancer, 83(1), 69-75.

Gerber, L. H., Hoffman, K., Chaudhry, U., Augustine, E., Parks, R., Bernad, M., ... Mansky, P. (2006).Functional outcomes and life satisfaction in long-term survivors of pediatric sarcomas.Archives of Physical Medicine and Rehabilitation, 87(12), 1611-1617.

Gerhardt, C. A., Dixon, M., Miller, K., Vannatta, K., Valerius, K. S., Correll, J., \& Noll, R. B. (2007).Educational and occupational outcomes among survivors of childhood cancer during the transition to emerging adulthood.Journal of Developmental and Behavioral Pediatrics, 28(6), 448-455.

Giele, J. Z. \& Elder, G. H. (1998).Methods of Life Course Research: Qualitative and Quantitative Approaches. Thousand Oaks: SAGE.

Gurney, J. G., Krull, K. R., Kadan-Lottick, N., Nicholson, H. S., Nathan, P. C., Zebrack, B., ... Ness, K. K. (2009). Social outcomes in the Childhood Cancer Survivor Study cohort.Journal of clinical oncology, 27(14), 2390-2395.

Haas, S. A. (2006). Health selection and the process of social stratification: the effect of childhood health on socioeconomic attainment, Journal of health and social behavior, 47(4), 339-354.

Hedström, P., \&Swedberg, R. (1998). Social Mechanisms: An Analytical Approach to Social Theory. Cambridge: Cambridge University Press.

Kazak, A. E., DeRosa, B. W., Schwartz, L. A., Hobbie, W., Carlson, C., Ittenbach, R. F., ... Ginsberg, J. P. (2010). Psychological Outcomes and Health Beliefs in Adolescent and Young Adult Survivors of Childhood Cancer and Controls.Journal of Clinical Oncology, 28(12), 2002-2007.

Kelaghan, J., Myers, M. H., Mulvihill, J. J., Byrne, J., Connelly, R. R., Austin, D. F., ... Holmes, G. F. (1988). Educational achievement of long-term survivors of childhood and adolescent cancer.Medical and pediatric oncology, 16(5), 320-326.

Kirchhoff, A. C., Krull, K. R., Ness, K. K., Park, E. R., Oeffinger, K. C., Hudson, M. M., ... Leisenring, W. (2011). Occupational outcomes of adult childhood cancer survivors: A report from the childhood cancer survivor study. Cancer, 117(13), 3033-3044.

Koch, S. V., Kejs, A. M. T., Engholm, G., Johansen, C., \&Schmiegelow, K. (2004). Educational attainment among survivors of childhood cancer: a population-based cohort study in Denmark. British journal of cancer, 91(5), 923-928.

Kuehni, C. E., Strippoli, M.-P. F., Rueegg, C. S., Rebholz, C. E., Bergstraesser, E., Grotzer, M., ... Swiss Pediatric Oncology Group (SPOG). (2012). Educational achievement in Swiss childhood cancer survivors compared with the general population.Cancer, 118(5), 1439-1449.

Lancashire, E. R., Frobisher, C., Reulen, R. C., Winter, D. L., Glaser, A., \& Hawkins, M. M. (2010). Educational attainment among adult survivors of childhood cancer in Great Britain: a population-based cohort study. Journal of the National Cancer Institute, 102(4), 254-270.

Langeveld, N. E., Grootenhuis, M. A., Voûte, P. A., de Haan, R. J., \& van den Bos, C. (2004). Quality of life, self-esteem and worries in young adult survivors of childhood cancer. Psycho-Oncology, 13(12), 867-881.

Lorenzi, M., McMillan, A. J., Siegel, L. S., Zumbo, B. D., Glickman, V., Spinelli, J. J., ... McBride, M. L. (2009). Educational outcomes among survivors of childhood cancer in British Columbia, Canada: report of the Childhood/Adolescent/Young Adult Cancer Survivors (CAYACS) Program. Cancer, 115(10), 2234-2245. 
Lund, L. W., Schmiegelow, K., Rechnitzer, C., \& Johansen, C. (2011). A systematic review of studies on psychosocial late effects of childhood cancer: structures of society and methodological pitfalls may challenge the conclusions. Pediatric Blood \& Cancer, 56(4), 532-543.

Mayer, K. U. (2009). New Directions in Life Course Research.Annual Review of Sociology, $35,413-433$.

Miles, M. B., \&Huberman, A. M. (1994). Qualitative Data Analysis: An Expanded Sourcebook. London: SAGE.

Mitby, P. A., Robison, L. L., Whitton, J. A., Zevon, M. A., Gibbs, I. C., Tersak, J. M., ... Mertens, A. C. (2003). Utilization of special education services and educational attainment among long-term survivors of childhood cancer: a report from the Childhood Cancer Survivor Study. Cancer, 97(4), 1115-1126.

Oeffinger, K. C., Mertens, A. C., Sklar, C. A., Kawashima, T., Hudson, M. M., Meadows, A. T., et al. (2006). Chronic health conditions in adult survivors of childhood cancer. The New England Journal of Medicine, 355(15), 1572-1582.

Palloni, A., Milesi, C., White, R. G., \& Turner, A. (2009). Early childhood health, reproduction of economic inequalities and the persistence of health and mortality differentials.Social science \& medicine, 68(9), 1574-1582.

Parsons, J. A., Eakin, J. M., Bell, R. S., Franche, R.-L., \& Davis, A. M. (2008). « So, are you back to work yet? » Re-conceptualizing 'work' and 'return to work' in the context of primary bone cancer. Social Science \& Medicine, 67(11), 1826-1836.

Pastore, G., Mosso, M. L., Magnani, C., Luzzatto, L., Bianchi, M., \&Terracini, B. (2001). Physical impairment and social life goals among adult long-term survivors of childhood cancer: a population-based study from the childhood cancer registry of Piedmont, Italy. Tumori, 87(6), 372-8.

Phillips, F., \& Jones, B. L. (2014). Understanding the lived experience of Latino adolescent and young adult survivors of childhood cancer. Journal of Cancer Survivorship, 8(1), $39-48$.

Prouty, D., Ward-Smith, P., \&Hutto, C. J. (2006). The lived experience of adult survivors of childhood cancer.Journal of Pediatric Oncology Nursing, 23(3), 143-151.

Ricoeur, P. (1984). Time and Narrative.University of Chicago Press.

Ross, C., \& Chia-Ling, W. (1995). The Links between Education and Health.American Sociological Review, 60(5), 719-45.

Schoon, I., \&Eccles, J.S. (2014). Gender Differences in Aspirations and Attainment: A Life Course Perspective. Cambridge: Cambridge University Press.

Servitzoglou, M., Papadatou, D., Tsiantis, I., \&Vasilatou-Kosmidis, H. (2008).Psychosocial functioning of young adolescent and adult survivors of childhood cancer.Supportive Care in Cancer, 16(1), 29-36.

Strauss, A., \& Corbin, J. M. (1998). Basics of Qualitative Research: Techniques and Procedures for Developing Grounded Theory. London: SAGE.

Super, D. (1957). The psychology of careers. New York: Harper \& Row.

Weber, M. (1978). Economy and Society: An Outline of Interpretive Sociology. Berkeley: University of California Press.

West, P. (1991). Rethinking the health selection explanation for health inequalities. Social Science \& Medicine, 32(4), 373-384.

Williams, G. (1984). The genesis of chronic illness: narrative re-construction. Sociology of Health and Illness, 6, 175-200. 
Zeltzer, L. K., Recklitis, C., Buchbinder, D., Zebrack, B., Casillas, J., Tsao, J. C. I., et al. (2009). Psychological status in childhood cancer survivors: a report from the Childhood Cancer Survivor Study. Journal of Clinical Oncology, 27(14), 2396-2404. 
Table 1. Characteristics of Euro2K participants a, according to sampling and participation into the qualitative study (\%)

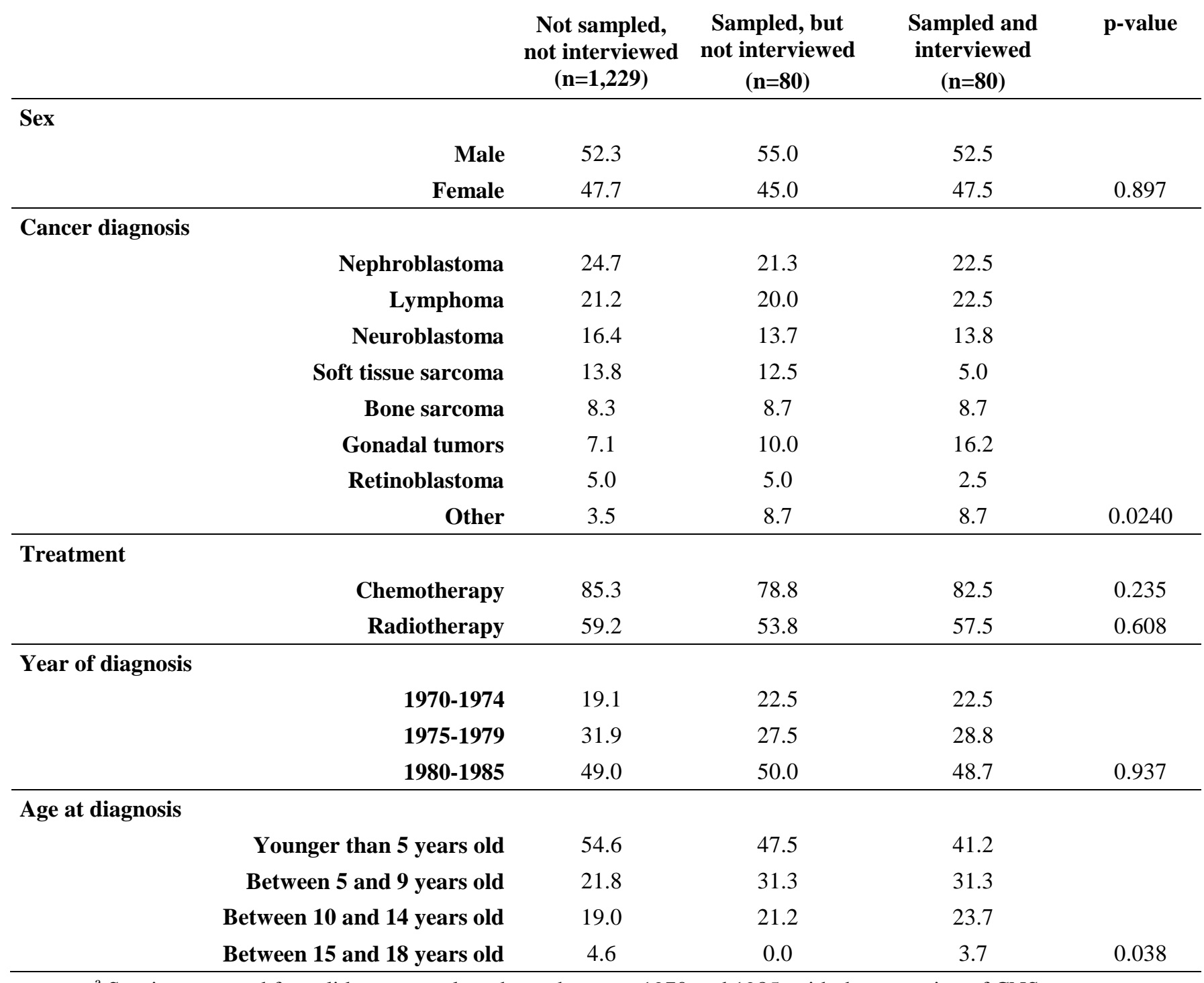

${ }^{\text {a }}$ Survivors treated for solid tumors or lymphoma between 1970 and 1985, with the exception of CNS tumors. 